\section{МЕНТАЛИТЕТ ТУВИНЦЕВ В ГОРИЗОНТЕ СОЦИОКУЛЬТУРНОЙ ФЕНОМЕНОЛОГИИ ПИТИРИМА СОРОКИНА}

\author{
Евгений А. Тюгашев \\ Новосибирский национальный \\ исследовательский государственный \\ университет, Россия,
}

\section{Юрий В. Попков}

Институт философии права Сибирского отделения Российской академии наук, Россия

\section{MINDSET OF TUVANS IN TERMS OF PITIRIM SOROKIN'S CULTURAL PHENOMENOLOGY}

В статье представлен оригинальный подход в исследовании этнического менталитета тувинцев, который заключается в его феноменологическом описании.

Подход строится на $\mathrm{cu}$ стематике соответствующих явлений, их типологии и классификации. В контексте формулируемых феноменологических теорий возможна не только индивидуализированная характеристика, но и эмпирическая диагностика менталитетов отдельных народов. В качестве фундаментальной базы для решения поставленной

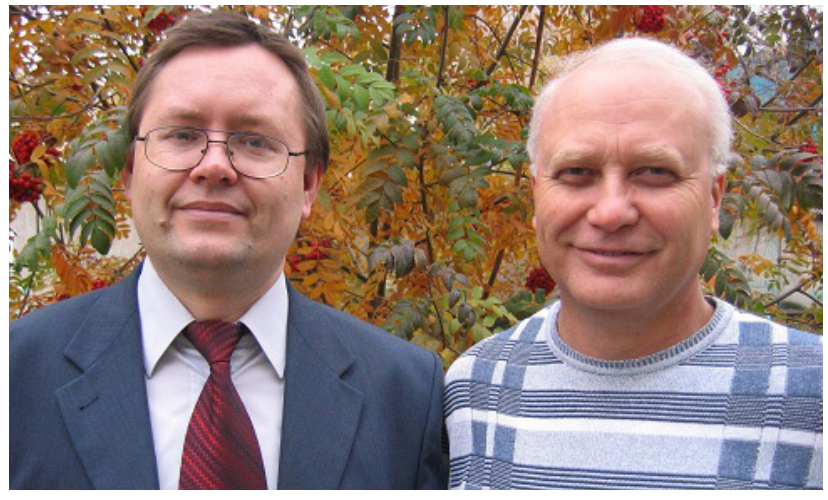

Institute of Philosophy and Law, Siberian Branch, Russian Academy of Sciences, Russian Federation

The article provides a new approach to studying the ethnical mindset of Tuvans - by creating its phenomenological portrait.

The approach is based on classifying a number of phenomena depending on their
Novosibirsk National Research State University, Russian Federation

Yuri V. Popkov types and categories. Not only do phenomenological theories help provide individualized characteristics of a nation's mindset, but also its empirical diagnostics. In terms of

Попков Юрий Владимирович - доктор философских наук, профессор, заместитель директора по научной работе и заведующий сектором этносоциальных исследований. Адрес: 630090, Россия, г. Новосибирск, ул. Николаева, д. 8. Тел.: +7 (383) 330-22-40. Эл. адрес: yuripopkov54@mail.ru

Тюгашев Евгений Александрович - кандидат философских наук, доцент кафедры теории и истории государства и права Института философии и права Новосибирского национального исследовательского государственного университета. Адрес: 630090, Россия, г. Новосибирск, ул. Пирогова, д. 2. Тел.: +7 (383) 269-67-42. Эл. адрес: filosof10@yandex.ru

Popkov Yuri Vladimirovich, Doctor of Philosophy, Professor; Deputy Director for Research, Head, Sector of Ethno-Social Studies, Institute of Philosophy and Law, Siberian Branch, Russian Academy of Sciences. Postal address: 8 Nikolaeva str., Novosibirsk, Russian Federation 630090. Tel.: +7 (383) 330-22-40. E-mail: yuripopkov54@mail.ru

Tyugashev Evgeny Aleksandrovich, Candidate of Philosophy, Associate professor, Theory and History of Law Department, Institute of Philosophy and Law, Novosibirsk National Research State University. Postal address: 2 Pirogova str., Novosibirsk, Russian Federation 630090. Tel.: +7 (383) 269-67-42. E-mail: tugashev@academ.org 
задачи используется творческое наследие выдающегося российско-американского социолога П. А. Сорокина, которое содержит развернутое феноменологическое учение о менталитетах культуpы. Именно это учение лежит в основании анализа тувинского менталитета.

Показано, что в категориях учения П. А. Сорокина социокультурная динамика менталитета тувинцев состоит в циклической смене псевдоидеационального и идеалистического менталитетов, из которых последний воспринимается как норма традиционной культуры.

Ключевые слова: менталитет; типология менталитетов; менталитет тувинцев; тувинцы; феноменология Питирима Сорокина; П. А. Сорокин; социокультурная феноменология; ментальные основы модернизации fundamental theory, our approach rests upon the works of prominent Russian-American sociologist P.A. Sorokin who developed a phenomenological doctrine of cultural mindsets. It is this theory that forms the background of our analysis of Tuvan mindset.

The article shows that in the context of Sorokin's theory, the sociocultural evolution of Tuvans' mindset consists of cyclic shifts between the pseudoideative and idealistic mindsets, and the latter is seen as a norm for traditional culture.

Keywords: mindset; typology of mindsets; mindset of Tuvans; Tuvans; Pitirim Sorokin's phenomenology; P.A. Sorokin; sociocultural phenomenology; mental concepts of modernization

\section{Введение}

Современные исследования этнического менталитета являются главным образом эмпирическими и осуществляются в рамках двух основных подходов. «Нормативный» подход состоит в качественном описании характерного для этноса содержания общественного сознания на примере прецедентных текстов и типичных, эталонных образцов культуры. Так описываются восприятие пространства и времени, представления о жизни и смерти и другие элементы содержания общественного сознания. Второй подход ориентирован на количественное измерение в опросах населения отдельных проявлений этнического менталитета через сравнение выраженности этнических авто- и гетеростереотипов. В этом случае удается зафиксировать эмпирически достоверные различия между менталитетами различных этносов по тем проявлениям, которые привлекли внимание исследователей.

В рамках данных подходов познавательное движение совершается на эмпирическом уровне в направлении от чувственно-конкретного к абстрактному. В результате формируется хаотическое представление о менталитете этноса. В этом представлении значимость отдельных элементов менталитета неочевидна, а их этническая специфика не всегда ясна. Мы получаем характеристику этнического менталитета в его индивидуальности и множестве разнообразных проявлений, но прикладная ценность такого описания невелика.

Поэтому в логике научного исследования первичное эмпирическое описание должно найти продолжение в феноменологии, т. е. в систематике явлений, их типологии и классификации. Систематизированное эмпирическое 
описание явлений завершается построением феноменологических теорий, объясняющих наблюдаемые явления посредством онтологических схем, эмпирическая значимость которых удостоверена. На наш взгляд, в исследованиях менталитета сейчас наиболее важен феноменологический (в общенаучном смысле этого термина) этап.

Задачей статьи является анализ тувинского менталитета в горизонте социокультурной феноменологии П. А. Сорокина (1889-1968). Феноменологическая программа Питирима Сорокина привлекла наше внимание потому, что она содержит развернутое учение о менталитете ${ }^{1}$ и его типах. Как представляется, не будет преувеличением сказать, что его теория социокультурной динамики по сути является теорией менталитетов. Поэтому наследие Питирима Сорокина, на наш взгляд, должно стать одним из важных источников в современных исследованиях менталитета. При этом построения знаменитого социолога не должны восприниматься как безусловные, абсолютно верные. Сами они требуют определенного критического отношения, поскольку являются не всегда достаточно последовательными. На этом далее также будет сделан акцент.

\section{Учение о менталитете в социокультурной феноменологии}

\section{П. А. Сорокина}

П. А. Сорокин обращал внимание на непрерывную изменчивость эмпирически фиксируемых социокультурных феноменов (явлений) (Сорокин, 2006: 797) и обусловленную этим непрерывную изменчивость эмпирических (т. е. феноменологических) социальных теорий (там же: 874). Он полагал возможным выявлять статистически значимые причинно-функциональные связи между переменными культуры (например, между плотностью населения и преступностью, коммерческими циклами и уровнем смертности и т. п.) (там же: 58). Кроме того, следуя Э. Гуссерлю, П. А. Сорокин полагал, что необходимо устанавливать «социально-объективный», логический смысл явления (там же: 931).

Менталитетом культуры он называл внутренний опыт, существующий «либо в виде хаотических и бессвязных образов, идей, стремлений, ощущений и эмоций, либо в виде упорядоченных систем мышления, сотканных из этих элементов внутреннего опыта...» (там же: 56). Эта внутренняя сторона культуры управляет ее внешней стороной и воплощается в поведении, предметах, событиях и процессах. Поэтому исследование культуры П. А. Сорокин предлагал начинать с описания ее менталитета.

На его взгляд, менталитет культуры допускает как психологическую интерпретацию, так и логическое понимание, основанное на выделении смысла

\footnotetext{
${ }^{1}$ Его термин «mentality» на русский язык обычно переводится как «ментальность».
} 
культуры. Этот смысл выступает большой посылкой (или ценностью) ментальности. В структуре большой посылки П. А. Сорокин выделял природу реальности, целей и потребностей, степень и способы их удовлетворения.

В хаосе культурных миров он выделил два основных типа культуры, обладающих собственным менталитетом: чувственную и идеациональную. Чувственную ментальность он подразделил на активную, пассивную и циническую. Идеационализм также делится на активный и пассивный. В качестве смешанных, слабо интегрированных типов менталитетов он выделил идеалистический и псевдоидеациональный.

Очевидно, что выдвинутое П. А. Сорокиным учение о менталитетах является по своему гносеологическому статусу: а) феноменологическим, поскольку типологизирует эмпирически данные явления; б) теоретическим, так как исходит из категориальной оппозиции чувственного (материального) и сверхчувственного (идеального); в) учением о философских менталитетах культур, ввиду того, что основывается на философских абстракциях. Таким образом, это феноменологическая теория базовых философских менталитетов, находящихся в основе культур.

Методологическое значение теории базовых философских менталитетов состоит в том, что абстрактно выделенные чувственный и идеациональный менталитеты предполагают комплексы тесно связанных с ними установок, ориентаций, идей (там же: 50). Так, в чувственной культуре преобладают эмпиризм, материализм и натурализм, динамизм и темпорализм, детерминизм, номинализм, этика счастья, удовольствия и пользы. В идеациональной культуре преобладают рационализм, мистицизм, идеализм, статика и этернализм, индетерминизм, схоластический реализм, этика абсолютных принципов. Поскольку из истории философии известны различные комбинации выделенных выше и других переменных, то эти комбинации можно применять для концептуальной схематизации эмпирических данных о той или иной культуре.

\section{Логическая некорректность типологии менталитетов}

\section{П. А. Сорокина}

Опираясь на систематизацию и статистическое обобщение обширного историко-культурного материала, П. А. Сорокин констатировал преобладание у различных народов в определенные периоды времени тех или иных типов менталитетов и соответствующих им форм социальных отношений. Так, к идеациональной культуре он относил Тибет с его ламаизмом и теократией.

Очевидно, что и динамика менталитета тувинцев может быть интерпретирована с точки зрения предложенной П.А. Сорокиным типологии менталитетов. 
Казалось бы, распространение буддизма в Туве позволяет отнести ее к странам с идеациональной культурой. Вместе с тем, известно, что в Туве отсутствовала теократия. Таким образом, культурные ситуации в Тибете и Туве различны. Это дает основания предполагать, что тибетский и тувинский менталитеты нетождественны.

Для диагностики тувинского менталитета представляется необходимым уточнить те концептуальные средства, которые мы обнаруживаем в учении П. А. Сорокина. Здесь остановимся на понятии менталитета, типологии менталитетов и циклической динамике менталитетов.

Напомним, что под менталитетом знаменитый социолог понимал совокупность образов, идей, стремлений, ощущений и эмоций, а также упорядоченных систем мышления. В описаниях различных менталитетов он выделял самые разные характеристики психики и сознания. Содержание менталитета четко не очерчивалось. Поэтому любые черты психологии этноса, элементов массового и специализированного общественного сознания могут быть отнесены к менталитету того или иного типа.

Предложенная П. А. Сорокиным типология менталитетов не вполне очевидна. Так, разделение на чувственный и идеациональный типы можно признать логически обоснованным. Последующее подразделение осуществлено по разным основаниям: чувственный менталитет делится на активный, пассивный и циничночувственный, а идеациональный - на активный и аскетический подтипы.

Кроме того, выделение циничного чувственного менталитета выглядит факультативным. Действительно, аналогичный подтип в составе идеационального менталитета П. А. Сорокин не выделил. Да и при характеристике циничного менталитета в качестве существенного признака указывалось на «попеременное надевание идеациональных масок» (там же: 66). Иначе говоря, циничный подтип фактически является псевдоидеациональным менталитетом.

В связи с этим выглядит проблематичным выделениеП.А. Сорокиным псевдоидеационального менталитета. Формально последний определялся как подтип смешанного менталитета, но фактически описывался как подтип чувственного менталитета, так как в нем характер реальности ощущается как чувственный, а потребности и цели - как преимущественно физические. Отмечается пассивность и вынужденный аскетизм данного менталитета. Перспективой его развития П. А. Сорокин считал чувственный менталитет. Поэтому не ясно, какие именно псевдоидеациональные черты присущи данному менталитету.

Указывая на определенную логическую некорректность типологии менталитетов П. А. Сорокина, все же подчеркнем, что благодаря обоснованности исходного деления эта типология имеет некоторый эвристический смысл. В силу этого она может быть переосмыслена и учтена при характеристике менталитетов отдельных культур. 


\section{Принцип развития в типологии менталитетов}

Для переосмысления представляется возможным принцип развития, неявно намечаемый П. А. Сорокиным. Так, на его взгляд, псевдоидеациональный менталитет развивается в чувственный менталитет. Аскетический идеационализм необходимо перерастает в активный идеационализм. Идеалистический менталитет формируется на основе синтеза идеационального и чувственного менталитетов.

Обратим внимание, что наиболее массовым и распространенным типом менталитета П.А. Сорокин считал псевдоидеациональный. С точки зрения принципа развития это означает, что он является древнейшим и первичным типом менталитета, а остальные являются вторичными и производными.

По многим элементам псевдоидеациональный менталитет характеризовался как полуживотный, смутный и нерасчлененный, недифференцированный. Поскольку дифференциация есть продукт развития, то данный менталитет находится в начале ментального развития. Более точно, он может быть определен как синкретический и архаический менталитет, если в данном случае архе понимать этимологически точно - как начало. Другие типы менталитетов характеризуются определенными акцентами и противопоставлениями, образующимися в результате процессов дифференциации и интеграции.

Псевдоидеациональный менталитет также может быть определен как генетически-практический, обыденный менталитет, поскольку его фрагменты формируются методом проб и ошибок. П. А. Сорокин подчеркивал, что псевдоидеациональный менталитет распространен в среде бедных и угнетенных классов, всех тех, «кто должен был из-за нужды и против своего желания заниматься делом, которое им не нравится» (там же: 95). Среди господствующих классов, наоборот, распространены все остальные типы менталитетов, адаптированные к благоприятным условиям жизни. «... Бедные и угнетенные классы более склонны к псевдоидеациональной ментальности, чем богатые, - писал П. А. Сорокин. - Обстоятельства не позволяют им быть пассивными или активными “эпикурейцами”. У них нет ни возможности, ни перспективы возвыситься до уровня активного идеационализма, и поэтому они должны довольствоваться своим положением, которое не позволяет им усвоить исключительно чувственную ментальность и манеру поведения» (там же: 85). Таким образом, псевдоидеациональный менталитет - менталитет масс, а остальные менталитеты - элитарны.

Псевдоидеациональный менталитет является базовым, наиболее массовым и, следовательно, всеобщим типом менталитета. Остальные типы менталитета элитарны, но они получают определенное распространение в массовом сознании, подчиняя себе или вытесняя псевдоидеациональный менталитет. Поэтому структура ментальности отдельного народа имеет сложную структуру, 
в которой те или иные подтипы менталитетов представлены в разных слоях в конкретных пропорциях. Обнаруживаемое при диагностике актуальное доминирование какого-либо подтипа менталитета и дает основание для ментальной идентификации конкретного народа.

При диагностике менталитета тувинцев важно учесть еще один аспект учения П. А. Сорокина о менталитетах - цикличность смены менталитетов. Историческая динамика менталитетов есть колебательный процесс, в котором получают преобладание то чувственный, то идеациональный менталитеты. Смена доминирования этих базовых менталитетов опосредствована идеалистическим менталитетом, в котором временно балансируются чувственные и идеациональные составляющие. В перспективе, согласно прогнозу социолога, этот баланс станет более устойчивым, а идеалистический менталитет станет финалом мировой истории.

Таким образом, с учетом представлений П. А. Сорокина, и в историческом развитии тувинского этноса может быть выделена определенная цикличность. Эта цикличность должна выражаться в смене доминирующих менталитетов.

\section{Диагностика менталитета тувинцев}

Изложенные предварительные соображения позволяют обратиться к диагностике менталитета тувинцев как он выглядит в рамках зафиксированной типологии П. А. Сорокина.

Приведем несколько этнопсихологических характеристик. Е. Н. Резников и Н. О. Товуу пишут: «Для тыва этноса можно отметить целостность и труднодоступность территории проживания. Борьба этноса тыва за выживание в условиях резко континентального климата сформировала такие психологические черты, как терпение, выносливость, практичность, рационализм, спокойствие и уравновешенность...» (Резников, Товуу, 2002: 37). Далее они дополнительно отметили такие социально-психологические особенности тувинцев как терпимость, чувство единой родоплеменной и национальной принадлежности, неприхотливость, самостоятельность, настойчивость, независимость, способность переносить трудности, эмоционально-волевая устойчивость, гостеприимность, чуткость, искреннее уважительное отношение к старшим и младшим, вежливость, уважение достоинства и чести других людей, самоограничение, самоуспокоенность, умеренность во всем, стремление к балансу и гармонии в жизни (там же: 45).

В более поздней публикации Н. О. Товуу подчеркивает целостность и историческую устойчивость тувинского народа и его культуры. Разнообразие ландшафтов сформировало у тувинцев любовь к природе, заботливое и бережное отношение к миру, умение наблюдать, находить и оберегать полезное в разных 
природных условиях. Суровость климатических условий и относительно изолированное проживание определили немногословность в общении, выносливость и жизнестойкость, неприхотливость и терпеливое отношение к трудностям, готовность к частым изменениям погоды, умение приспосабливаться к суровой природе местности (Товуу, 2014: 123-124). По оценке Н. О. Тувуу, у подавляющей части тувинцев сформировался флегматичный темперамент (движения неторопливы, уравновешены и сдержаны, темп жизни несколько замедлен) (там же: 125).

Ч. К. Ламажаа тувинский национальный характер определяется как «резкоконтинентальный». В сочетании черт характера она обращает внимание на созерцательность, художественность, непунктуальность, флегматизм, любовь к детям, групповое соперничество, завистливость (Ламажаа, 2013).

Приведенные характеристики позволяют сделать определенные выводы в отношении типологической принадлежности менталитета тувинцев.

Прежде всего, нельзя утверждать, что он относится к классу активных подтипов - активному идеационализму и активно-чувственному менталитету. Это вытекает из созерцательности тувинцев, свойственной, впрочем, многим кочевым народам.

Разумеется, также нельзя идентифицировать тувинский менталитет как аскетически-идеациональный, поскольку тувинцы не стремились к трансцендентальным ценностям, а богатство традиционно видели в количестве скота, детей, родни, в долгожительстве.

Таким образом, у тувинцев идеациональный менталитет явно не доминирует.

Циничный и пассивно-чувственный менталитеты у тувинцев также слабо выражены.

Так, тувинцы не склонны к цинизму и нигилизму, обману и лицемерию.

По П. А. Сорокину, признаками пассивно-чувственного менталитета являются отсутствие настоящего контроля над собой и средой, паразитизм, жизнь под девизом «Вино, женщины, песня». Такие проявления, действительно стали наблюдаться в последние десятилетия. «Часть тувинцев, не вписавшихся в новые социальные требования, не просто молча принимает помощь от более удачливых родственников, не соразмеряя свой вклад в общесемейное распределение сил, но и настаивает на оказании помощи им. Речь идет не только о расцвете старой родовой солидарности, о расцвете клановых отношений, но и о распространении их превращенных форм - общественного паразитизма и безалаберности», - констатирует Ч. К. Ламажаа (Ламажаа, 2016: Электр. ресурс). Эти проявления действительно присутствуют, но оцениваются в общественном сознании как девиация, отклонение от традиционного тувинского менталитета. 
Поскольку у тувинцев не выражен активно-чувственный и циничночувственные типы менталитета, а пассивно-чувственный тип воспринимается как девиация, то в целом можно сделать вывод о том, что чувственный менталитет для тувинцев в целом не характерен.

Из семи выделенных П. А. Сорокиным типов менталитета, возможно относящимися к тувинцам, остаются идеалистический и псевдоидеациональный менталитеты.

\section{Циклизм псевдоидеационального и идеалистического}

\section{менталитетов}

Учитывая описание тувинского характера как «резко-континентального», возможной представляется идентификация менталитета тувинцев как псевдоидеационального. Его формирование обусловлено суровыми природноклиматическими условиями. Признаками псевдоидеационального менталитета являются бедность, сильно ограниченная степень удовлетворения потребностей. Способ удовлетворения потребностей заключается в вынужденном терпении среды. Чужое насилие, производимое внешней властью, также просто терпится.

Наряду с этим нельзя утверждать, что все признаки псевдоидеационального менталитета присущи тувинцам. Псевдоидеациональный менталитет является смутным и нерасчлененным, недифференцированным. Менталитет же тувинцев дифференцирован. В тувинской мифологической картине мира противопоставлены хаос и космос, три мира - Верхний, Средний и Нижний, присутствует числовая символика. Таким образом, реальность в ментальности тувинцев дифференцирована. Более того, она сложно организована, так как в ней, как замечает Ч. К. Ламажаа, «одновременно также сосуществуют, спрессованы несколько “природных зон” или черт. Причем, не противоположные друг другу, как у русских в трактовке Н. А. Бердяева, но сложно сочетающиеся. Несовместимые друг с другом, но все же сложившиеся в какой-то удивительно тугой и многослойный узел» (там же).

Органичное сплетение различных типов культурных ментальностей представлено в виде синкретизма шаманизма и буддизма. Этот синкретизм, с одной стороны, характеризуется дистанцированностью между шаманами и ламами, но с другой стороны выступает как сплав, компоненты которого взаимопроникают и взаимоадаптированы. Общепризнанный факт указанного синкретизма позволяет предположить наличие у тувинцев идеалистического менталитета.

Действительно, в традиционной ментальности тувинцев в равной мере представлены чувственно-материальная реальность и мир духов, т. е. духовная реальность. Эти реальности в определенной степени контролируются. Как 
и представители идеалистической ментальности, тувинцы придерживаются принципа «живи сам и давай жить другим». «Если человек берет что-то в природе (т. е. у чер ээлери), - поясняет Б. А. Мышлявцев, - он должен в ответ отблагодарить хозяев - “помолиться”, чем-нибудь угостить духов» (Мышлявцев, 2009: Электр. ресурс). Именно поэтому тувинцы отрицательно оценивают стремление к обогащению, нарушающее мировую гармонию. «Связано это, так же как и требования добывать зверя в умеренных количествах, (и вообще многие нормы природопользования), - продолжает Б. А. Мышлявцев - с представлением об общности дарованной всем людям (Бурганом, духами-хозяевами мест) доли. Человек, присваивающий себе чужую долю, нарушает, таким образом, социальную и мировую гармонию и является для общества опасным» (там же).

Наблюдение о мировой гармонии как элементе тувинского менталитета является дополнительным аргументом в отнесении его к идеалистическому типу. В таком случае менталитет тувинцев должен выступать как целостный и внутренне интегрированный. Именно так он и воспринимается экспертами. Но в таком случае возникает вопрос о том, какая категория выступает фундаментальной ценностью, большой посылкой тувинской культуры?

На наш взгляд, попытку выделить такую категорию предпринял Б. А. Мышлявцев: «Итак, категория уважения, основанная на ценности упорядоченности, является для тувинской нормативной культуры базовой» (там же). Уважение состоит в признании формального статуса субъекта и выражается в дарообмене. Принцип уважения действует и в отношения тувинцев с духами-хозяевами: «К ним никто не испытывает любви, их именно уважают, причем в точном соответствии с их рангом - к духу, хозяину большой местности, относятся с большим уважением, чем к духу невысокого ранга» (там же).

Думается, что вывод Б.А. Мышлявцева об уважении как базовой категории тувинского менталитета можно принять в качестве рабочей гипотезы. Не будем здесь обсуждать достаточность эмпирического обоснования этой гипотезы и степень ее теоретической проработки. Для нас принципиально важно лишь то обстоятельство, что базовые посылки тувинской культуры «просматриваются». Следовательно, положение об интегрированном и идеалистическом характере тувинской ментальности находит определенное подтверждение.

Итак, тувинский менталитет может быть интерпретирован как идеалистический. Наряду с этим, как показано выше, с учетом фактора суровых природноклиматических условий он диагностируется и как псевдоидеациональный менталитет. В результате возникает антиномия, отображающая действительное противоречие в динамике тувинского менталитета.

Данное противоречие Б. А. Мышлявцев описывает как ситуационное применение тувинцами традиционной и девиантной (маргинальной) моделей поведения. Традиционная модель реализуется во взаимном уважении занимае- 
мых статусных позиций и основана на «идеальной» норме, которая может быть интерпретирована как выражающая идеалистический менталитет. Тувинцы реализующие данную модель, воспринимаются как люди «безответные» и «тихие», «мирные» и «смирные». Девиантная модель поведения, выражающаяся в асоциальности и повышенной конфликтности, базируется на нормах, сформировавшихся в местах лишения свободы. Следовательно, она может быть интерпретирована как основанная на псевдоидеациональном менталитете. По оценке Б. А. Мышлявцева, эта модель реализуется в условиях ослабления внешнего силового давления и возникновения статусной неопределенности.

По мнению данного исследователя, в истории тувинского народа можно выявить определенную цикличность в реализации данных моделей поведения. Девиантная модель была заметной во 2-й половине XVIII в., в 1870-е гг., после поражения России в русско-японской войне, а также во время гражданской войны.

В категориях учения П. А. Сорокина эта цикличность может быть интерпретирована как периодическое преобладание идеалистического и псевдоидеационального менталитетов. Базовым является псевдоидеациональный менталитет, формируемый суровыми природно-климатическими условиями и неопределенностью внешнего, хаотично-враждебного окружения. В более благоприятных внешних условиях, при стабильности вертикали власти и четкой определенности социальных статусов, происходит инверсия и актуализируется идеалистический менталитет, закрепляемый в традиции.

\section{Ментальные основы модернизации}

Б. А. Мышлявцев высказывает мнение о том, что для современных тувинцев возврат к традиционному хозяйству и образу жизни мог бы сделать включение в процессы глобализации более «мягким», естественным. Это стратегия традиционализации. Но, очевидно, что в условиях глобализации, транснациональные корпорации нарушат замкнутость бытия. Поэтому модернизация неизбежна, и вопрос лишь в том: будет ли ей сопутствовать прогрессирующая маргинализация?

Ч. К. Ламажаа полагает, что тувинский этнос располагает определенными ресурсами модернизации. По ее мнению, в концепции модернизации главным объектом внимания должны стать люди и качество их жизни (Ламажаa, 2011: 280-305). Как же соединить потребность в традиционализации и необходимость модернизации, исходя из особенностей менталитета?

Ч. К. Ламажаа подчеркивает, что «безусловно, у тувинцев присутствуют традиционные отношения жесткого господства и подчинения» (Ламажаa, 2011: 352). Жесткость отношений, типичная для идеационального менталитета, сосуществует с отмеченной Б. А. Мышлявцевым потребностью в четкой определен- 
ности социального статуса, с позиций которого возможно легитимное соперничество. Если такая среда в Туве сейчас отсутствует, то тувинцев необходимо рекрутировать в соответствующие внешние среды вне Тувы.

Наиболее подходящей средой является служба в ведомствах силового блока. По-видимому, одним из каналов этнической мобилизации может быть «мобилизация» молодежи на военную службу и, прежде всего, обучение в образовательных организациях ведомств силового блока. В пределах республики также возможна определенная «милитаризация» социализации подрастающего поколения через кадетские корпуса, а также соответствующие досуговые формы. Как известно, армия всегда была важным фактором модернизации традиционных обществ, и в современной России «силовики» играют весьма значимую роль в управлении государством. Культ «милитаризма» может опираться на этнические традиции и способен расколдовать тувинский хронотоп.

Еще один канал этнической мобилизации - это использование механизма психологического отбора руководителей. По П. А. Сорокину, параметром, характеризующим активность менталитета, является интровертность/экстравертность. В идеалистическом менталитете, эти психологические типы представлены в равной мере. Псевдоидеациональный менталитет является вынужденно-интровертным-экстравертным, фаталистическим.

Ч. К. Ламажаа подчеркивала, что проблематика психологических типов тувинцев - еще «неизведанное поле», которое ждет своих исследователей (Ламажаa, 2013: 94-95). Вместе с тем, из общего описания тувинского характера, а также из факта доминирования среди тувинцев флегматического темперамента, следует, что Тува интровертна. С точки зрения предпочтительности того или иного психологического типа для структур власти, принято считать, что руководителями должны быть экстраверты. В частности, формулируется требование (закон) о необходимости экстравертного правительства в государстве, которое хочет хозяйственного развития, и интровертного правительства, если население довольно достигнутым страной материальным уровнем (Золотарев, 1997). Поскольку население Тувы явно не довольно своим благосостоянием, то для него требуется экстравертное руководство.

\section{Заключение}

Таким образом, представляется возможной эмпирическая диагностика тувинского менталитета в горизонте социокультурной феноменологии П.А.Сорокина. Творческое наследие выдающегося социолога содержит развернутое учение о менталитетах культуры, которое практически остается вне поля зрения исследователей, поскольку в фокусе их внимания находится культура. Анализ учения о менталитете П. А. Сорокина позволяет зафиксировать его основания, 
перспективы дальнейшей разработки и применения в отношении локальных культур, которые не нашли отражения в его исследованиях. На наш взгляд, в категориях учения П. А. Сорокина социокультурная динамика менталитета тувинцев может быть описана как циклическая смена псевдоидеационального и идеалистического менталитетов, из которых именно последний воспринимается как норма традиционной культуры.

\section{СПИСОК ЛИТЕРАТУРЫ}

Золотарев, Ю. (1997) Возможен ли прогресс в интровертном государстве (Взгляд соционика на Литву, в которой он живет) // Социон. № 2. С. 33-35.

Ламажаa, Ч. К. (2011) Тува между прошлым и будущим. 2-е изд. СПб. : Алетейя. 368 с.

Ламажаa, Ч. К. (2013) Тувиноведение : новые горизонты. М. : Книжный дом «Либроком». 184 с. С. 64-95.

Ламажаa, Ч. К. (2016) Национальный характер тувинцев [Электронный ресурс] // РГНФ. URL: www.rfh.ru/downloads/Books/16-43-93524.pdf (дата обращения: 02.05.2017).

Мышлявцев, Б. А. (2009) Нормативная культура тувинцев (конец XX - начало XXI в.) [Электронный ресурс] // Samlib.ru. URL: http://samlib.ru/m/myshljawcew_ boris_aleksandrowich/tuva-1.shtml (дата обращения: 02.05.2017).

Резников Е. Н., Товуу, Н. О. (2002) Этнопсихологические характеристики народа тыва: теория и практика. М. : ПЕР СЭ. 223 с.

Сорокин, П. А. (2006) Социальная и культурная динамика / пер. с англ. М. : Астрель. 1176 с.

Товуу, Н. О. (2014) Этнос тыва как социальная группа макрообщности: факторы формирования облика // Scientific e-journal «PEM: Psychology. Educology. Medicine». № 3. C. 121-132.

Дата поступления: 27.06.2017 2.

\section{REFERENCES}

Zolotarev, Iu. (1997) Vozmozhen li progress v introvertnom gosudarstve (Vzgliad sotsionika na Litvu, v kotoroi on zhivet) [Is progress possible in introverted state?: A socionicist's view of the Lithuania he lives in]. Sotsion, no. 2, pp. 33-35. (In Russ.)

Lamazhaa, Ch. K. (2011) Tuva mezhdu proshlym i budushchim [Tuva between the past and the future]. 2nd ed. St. Petersburg, Aleteiia. 368 p. (In Russ.) 
Lamazhaa, Ch. K. (2013) Tuvinovedenie : novye gorizonty [Tuvinology : the new horizons]. Moscow, Knizhnyi dom «Librokom». 184 p. Pp. 64-95. (In Russ.)

Lamazhaa, Ch. K. (2016) Natsional'nyi kharakter tuvintsev [The national character of Tuvans]. RGNF [online] Available at: www.rfh.ru/downloads/Books/16-43-93524. pdf (access date: 02.05.2017). (In Russ.)

Myshliavtsev, B. A. (2009) Normativnaia kul'tura tuvintsev (konets XX - nachalo XXI v.) [The normative culture of the Tuvans (late 20th - early 21st centuries)]. Samlib. $r u$ [online] Available at: http://samlib.ru/m/myshljawcew_boris_aleksandrowich/ tuva-1.shtml (access date: 02.05.2017). (In Russ.)

Reznikov E. N. and Tovuu, N. O. (2002) Etnopsikhologicheskie kharakteristiki naroda tyva: teoriia i praktika [Ethno-psychological characteristics of the people of Tuva: theory and practice]. Moscow, PER SE. 223 p. (In Russ.)

Sorokin, P. A. (2006) Sotsial'naia i kul'turnaia dinamika [Social and cultural dynamics]. Moscow, Astrel'. 1176 p. (In Russ.)

Tovuu, N. O. (2014) Etnos tyva kak sotsial'naia gruppa makroobshchnosti: faktory formirovaniia oblika [The Tuvan ethnos as a social group of microosmotic: shaping factors]. PEM: Psychology. Educology. Medicine, no. 3, pp. 121-132. (In Russ.)

Submission date: 27.06.2017.

Для циитирования:

Тюгашев Е. А., Попков Ю. В. Менталитет тувинцев в горизонте социокультурной феноменологии Питирима Сорокина [Электронный ресурс] // Новые исследования Тувы. 2017, № 3. URL: https://nit.tuva.asia/nit/article/view/723 (дата обращения: дд.мм. гг.). DOI: $10.25178 /$ nit.2017.3.1

\section{For citation:}

Tyugashev E.A., Popkov Yu.V. Mindset of Tuvans in terms of Pitirim Sorokin's cultural phenomenology. The New Research of Tuva, 2017, no. 3 [on-line] Available at: https://nit. tuva.asia/nit/article/view/723 (accessed: ... ). DOI: 10.25178/nit.2017.3.1 